\title{
Dexmedetomidine provides better hemodynamic stability than fentanyl without impairing microcirculation during isoflurane anesthesia in bitches with pyometra submitted to ovariohysterectomy
}

Julio Ken Nagashima

Universidade de Sao Paulo

Lucas Alaião Gonçalves

Universidade de Sao Paulo

Marco Aurélio Amador Pereira

Universidade de Sao Paulo

Mariana Semião Francisco Talib

Universidade de Sao Paulo

Clair Motos de Oliveira

Universidade de Sao Paulo

Aline Magalhães Ambrósio

Universidade de Sao Paulo

Denise T. Fantoni ( $\square$ dfantoni@usp.br)

Universidade de Sao Paulo https://orcid.org/0000-0001-8783-5235

Research article

Keywords: OPS, dexmedetomidine, sepsis, pyometra, fentanyl

Posted Date: August 28th, 2019

DOI: https://doi.org/10.21203/rs.2.12879/v1

License: (c) (i) This work is licensed under a Creative Commons Attribution 4.0 International License.

Read Full License 


\section{Abstract}

Microcirculatory disorders are one of the most common systemic alterations in septic patients, which can occur even in the presence of normal macro-hemodynamic parameters. Several anesthetic protocols have been indicated for sepsis. A drug frequently used in critically ill human patients is dexmedetomidine, a potent and selective alpha 2-agonist with sedative, analgesic and muscle relaxant properties that promotes blood pressure increase and peripheral vasoconstriction. The objective of the present study was to compare dexmedetomidine and fentanyl constant rate infusions in septic dogs using microcirculatory, hemodynamic and metabolic parameters. Thirty-three bitches with pyometra submitted to therapeutic ovariohysterectomy (OHE) and triaged with the quick SOFA score were included in the study. The animals were randomized into two groups treated with either dexmedetomidine $(3 \mu \mathrm{g} / \mathrm{kg} / \mathrm{h})$ or fentanyl $(5 \mu \mathrm{g} / \mathrm{kg} / \mathrm{h})$ constant rate infusions during isoflurane anesthesia and under mechanical ventilation. Hemodynamic, microcirculatory, ventilatory and metabolic parameters were recorded before, during and after anesthesia. The data were submitted to a normality test, then groups were compared using the unpaired Wilcoxon test or the t student test when necessary. All microcirculatory parameters were not significantly different between groups. Dexmedetomidine constant rate infusion provided superior blood pressure values and lactate clearance results, suggesting that it did not impair peripheral oxygen transport and organ perfusion, and both groups had similar clinical outcomes such as mortality and occurrence of hypotension and bradyarrhythmias. Similar values of microcirculatory parameters and higher blood pressure demonstrated that dexmedetomidine does not compromise microcirculation compared to fentanyl, it improves macro-hemodynamics instead.

\section{Background}

Sepsis is a challenging clinical condition and one of the most important causes of morbidity and mortality in veterinary and human medicine (1). Patients with reduced tissue oxygenation due to a compromised cardiovascular system support the importance of monitoring the microcirculation during anesthesia and intensive care treatment in sepsis (2). Microcirculation plays an essential role in oxygen and other nutrients delivery, tissue perfusion and fluid homeostasis (3)

One of the most important parameters to be monitored during anesthesia of septic patients is the arterial blood pressure. However, even if the macro-hemodynamic goals are achieved, it's the coherence and the balance between them and the microcirculation that should be pursued. These parameters can provide better information regarding tissue oxygenation and its influence on patient outcome (2).

Constant rate infusions for analgesic purposes are largely used in veterinary anesthesia. Dexmedetomidine is a highly selective alpha 2 adrenergic receptor agonist that is considered a versatile anesthetic drug due to its analgesic and anesthetic-sparing effects, and it is also a valuable option in the intensive care unit scenario thanks to its sympatholytic properties (4). While its use is already a reality in mechanically ventilated human patients that require sedation in intensive care units (4), there is a lack of reported studies with dexmedetomidine in veterinary critically ill patients. 
The orthogonal polarization spectral imaging (OPS) technique allows the evaluation of microcirculation through the sublingual mucosa (5). It is a non-invasive procedure that can be performed at bedside and has been widely used in studies that evaluated microcirculation both in experimental and clinical scenarios.

We designed a randomized clinical trial to compare dexmedetomidine and fentanyl constant rate infusions (CRIs) in the anesthesia of septic dogs by analyzing hemodynamic, delta temperature and oxygen tissue perfusion parameters, aiming to test the hypothesis that the alpha 2 agonist provides hemodynamic stability with minimal undesirable impact on microcirculation compared to fentanyl.

\section{Methods}

\section{Animals}

This randomized clinical trial was approved by the Ethical Committee on Animal Use (Comissão de Ética no Uso de Animais-protocol number 3578080716) and performed at the Veterinary Hospital of the School of Veterinary Medicine and Animal Science of the University of Sao Paulo from January to November of 2016. Written informed consent was obtained from the patients' owners.

Female dogs diagnosed with pyometra through anamnesis, physical examination, laboratory and ultrasonographic findings were included in the study. According to The Third International Consensus Definitions for Sepsis and Septic Shock (Sepsis-3) (6), and based on the Quick SOFA criteria, patients were excluded when they showed at least one of the following characteristics: severe neurological disorder (Glasgow<13); mean arterial pressure lower than $60 \mathrm{mmHg}$ even after administration of intravenous volume replacement and vasopressors. Other exclusion criteria were heart disease (stage B2 or $\mathrm{C}$ of ACVIM consensus statement) or diabetes. All patients were submitted to laboratory tests including complete blood count and serum biochemistry profile (creatinine, urea, alanine aminotransferase, alkaline phosphatase, total serum protein). In the presence of comorbidities, other diagnostic exams were performed.

\section{Anaesthesia}

Cephalotin $(30 \mathrm{mg} / \mathrm{kg})$ and metronidazole $(15 \mathrm{mg} / \mathrm{kg})$ were established as the antibiotic protocol for all patients, which was initiated before the surgical procedure. All patients were pre-medicated with tramadol $3 \mathrm{mg} / \mathrm{kg}$ given intramuscularly (IM) and anesthesia was intravenously (IV) induced with propofol 2-5 $\mathrm{mg} / \mathrm{kg}$ titrated so that the patient permitted orotraqueal intubation. The anesthetic maintenance was performed with isoflurane (1.2\%) diluted in $70 \%$ oxygen. Rocuronium $0.6 \mathrm{mg} / \mathrm{kg}$ was used for neuromuscular blockade and mechanical ventilation was instituted with 12-22 breaths per minute (according to $\mathrm{PaCO}_{2}$ values) and a peak inspiratory pressure of $8-12 \mathrm{cmH}_{2} \mathrm{O}$ by means of an inhalation anesthesia equipment connected to a microprocessor-controlled ventilator (Inter Linea - Interlinea, Brasil). Capnography parameters and end-tidal isoflurane concentration were monitored with a side-stream gas 
analyzer (8500Q POET ${ }^{\circledR}$ IQ2 - Criticare Systems inc., EUA) and arterial blood gas analysis were performed (Cobas b121-Roche, Switzerland).

\section{Study Design}

Dogs were randomized into two groups (www.randomization.com), one of which received $6 \mathrm{~g} / \mathrm{kg} / \mathrm{hour}$ of fentanyl ${ }^{1}$ diluted in $0.9 \%$ saline solution at a $25 \mathrm{~g} / \mathrm{mL}$ concentration, and the other received $3 \mathrm{~g} / \mathrm{kg} / \mathrm{hour}$ of dexmedetomidine ${ }^{2}$ diluted in $0.9 \%$ saline solution at a $12.5 \mathrm{~g} / \mathrm{mL}$ concentration. The constant rate infusion was initiated 10 minutes before the surgery began. Dogs in the fentanyl group received 0,04 $\mathrm{mg} / \mathrm{kg}$ of atropine IM and a loading dose of $2,5 \mathrm{~g} / \mathrm{kg}$ of fentanyl IV (diluted in $3 \mathrm{~mL}$ of $0.9 \%$ saline solution and administered in 1 minute) in the moment the CRI was initiated, while dogs in the dexmedetomidine group did not receive a loading dose. Adjustments in the CRI doses (increase or decrease of $0.05 \mathrm{~g} / \mathrm{min} / \mathrm{h}$ for both drugs) were made if oscillations of at least $15 \%$ in blood pressure and heart rate values were observed.

\section{Monitoring}

Fluid therapy was performed with $5 \mathrm{~mL} / \mathrm{kg} / \mathrm{h}$ of lactated Ringer's solution administered by an infusion pump (DigiPump ${ }^{\circledR}$ IP88x-Digicare, Brasil). A heating pad (Med-Sinal-São Paulo) was placed under the patients to avoid hypothermia.

Both cephalic veins were catheterized for fluids and drugs administration and for blood samples collection. An arterial catheter was placed in the metatarsal artery to monitor arterial pressure. Heart rate, esophageal temperature, invasive arterial blood pressure (systolic, mean and diastolic) and pulse pressure variation (PPV) were recorded with a multiparameter monitor (DX 2020, Dixtal, São Paulo, SP, Brasil). Furthermore, blood samples for measuring serum lactate concentration, glycemia and blood gas analysis were collected at specific time points. Delta temperature was obtained by calculating the difference between esophageal (central) and peripheral temperatures, which was measured with an infrared digital thermometer (Infra.Term - Incoterm®, Brasil).

If the mean arterial pressure (MAP) was lower than $60 \mathrm{mmHg}$, the following intervention was performed: in patients showing a PPV greater than $15 \%$, a bolus of $15 \mathrm{~mL} / \mathrm{kg}$ of lactated Ringer's solution (IV) was administered in 15 minutes; a second fluid bolus could be administered if PPV remained $>15 \%$, until a MAP > 60mmHg was reached. If PPV was lower than $15 \%$, an ephedrine bolus of $0.25 \mathrm{mg} / \mathrm{kg}$ (IV) was administered; a second bolus could be administered until the MAP reached values $>60 \mathrm{mmHg}$. Nonresponsive hypotension with a PPV $<15 \%$ was treated with norepinephrine constant rate infusion $(0.1$ $\mu \mathrm{g} / \mathrm{kg} / \mathrm{min}$ ).

Images of the sublingual microcirculation were obtained with the OPS device (MicroScan ${ }^{\circledR}$ - MicroVision Medical Inc., Amsterdam, The Netherlands). The probe of the equipment was placed on the sublingual 
mucosa. Images from at least two different regions were recorded and saved on a computer drive for later editing and analysis with the Automated Vascular Analysis (AVA software 3.2-Microvision Medical, Amsterdam, The Netherlands), which is supplied by the manufacturer of the equipment. A single blind evaluator evaluated the images with the help of the software, which generated quantitative analyzes of microvascular flow index (MFI), capillary density (TVD-total vessel density) and DBS-De Backer Score, according to De Backer (7).

Briefly, MFI is an index obtained by dividing the images into four parts and classifying the flow in each quadrant as either absent, continuous, intermittent or decreased. This score depends on the visual evaluation of the vascular flow velocity in the dynamic images. TVD (total vessel density) in $\mathrm{mm} / \mathrm{mm}^{2}$, is based on the number of vessels crossing three horizontal and three vertical equidistant lines displayed on the screen by the program. DBS (De Backer score), which is also measured in $\mathrm{mm} / \mathrm{mm}^{2}$, was calculated by the software after adequate calibration and selection of the desired image sequence for analysis.

After surgery, patients were monitored for temperature, non-invasive blood pressure and level of consciousness during two hours in a heated room. Depending on their clinical evolution, a choice between intensive care hospitalization or discharge to home care was made.

The parameters evaluated in the present study were measured in the following times points: BASAL, about 30 minutes before anesthetic induction; T0, immediately before the beginning of fentanyl or dexmedetomidine $\mathrm{CRI} ; \mathrm{T} 30,30$ minutes past the initiation of the CRI; T60, 60 minutes after the beginning of the CRI; and FINAL, 60 minutes after extubation, with the patient already in the anesthesia recovery room.

Parameters evaluation time points are demonstrated in figure 1.

\section{Statitical analysis}

Data were presented as mean \pm standard deviation (SD) or median (interquartile range) when applicable. The normality of the data was assessed by the Shapiro-Wilk test, and to verify if values presented equal variances, the Bartlett test was used. For the comparison of hemodynamic, respiratory and metabolic variables between groups, the unpaired t-student test or the Mann-Whitney test were used. Furthermore, the comparison between moments of evaluation was performed with the ANOVA test for Tukey's repeated and post-hoc measurements or with the Kruskall-Wallis test with Bonferroni post-hoc. The significance level established for the statistical analysis was $5 \%(p<0.05)$. The tests were carried out in a computer program (RStudio, Version 0.99.903 - (c) 2009-2016 RStudio, Inc.).

\section{Results}

Thirty-eight female dogs with pyometra were enrolled in the study, however five had to be excluded due to diabetes mellitus (1 patient), difficulties in artery catheterization for measuring blood pressure invasively 
(1 patient) or low level of consciousness (3 patients with reduced Glasgow score). Therefore, thirty-three patients were included, 17 of which received dexmedetomidine and 16 received fentanyl.

There were no significant differences between groups regarding characteristics such as weight [15 $(5,4 / 30,8) \mathrm{kg}]$ and age $(9,2 \pm 3,8$ years). Concerning the pre-anesthetic laboratory tests, only creatinine and urea showed significant difference between groups (table 1 ).

Regarding clinical parameters, there were significant differences between groups in all time points during surgery (T0, T30, T60), as it is displayed in table 2. Values of systolic, diastolic, mean arterial pressures and delta temperature were significantly higher in the dexmedetomidine group. However, heart rate was significantly lower in the dexmedetomidine group in the same time points.

TVD and DBS did not differ significantly between groups, while MFI was significantly higher in the fentanyl group in T30 (table 3).

Blood gas analysis, $\mathrm{ETCO}_{2}$ (end-tidal carbon dioxide concentration) and ISO (end-tidal isoflurane concentration) with mean values \pm standard deviation and median / interquartile range are displayed in table 4.

Regarding the comparison of serum lactate concentration between moments, the FENTA group did not show significant differences $(p=0.189)$. However, there was a significant difference between T0 and T60 in the DEX group $(p=0.019)$. In the comparison between groups, there were no significant differences (figure 2).

\section{Discussion}

This was the first study evaluating the use of dexmedetomidine CRI in the anesthesia of septic dogs and comparing its hemodynamics, ventilatory and microcirculation effects with fentanyl's under the same conditions. According to the results found, the infusion of dexmedetomidine at a dose of $3 \mathrm{~g} / \mathrm{kg} / \mathrm{h}$ during isoflurane anesthesia provided hemodynamic stability and higher values of systolic, mean and diastolic blood pressure and delta temperature compared to fentanyl, without compromising the sublingual microcirculation.

The OPS imaging technique is a noninvasive method used to evaluate microcirculation in humans $(8,9)$, as it can reveal significant alterations in blood flow and decreased vascular density associated with microcirculatory derangements (9). Microcirculation is the main site of oxygen exchange between blood and adjacent tissues, and its homeostasis is altered in sepsis (10). In this study, there were no significant differences between the groups DEX and FENTA regarding the microcirculation evaluation with OPS, except for the microcirculatory flow index (MFI) at a single time point (T30), which indicated better results in the fentanyl group. It's important to remember that the total vascular density (TVD) and the De Backer score (DBS) provide vessel density information, while MFI is a flow quality index. These parameters correlate with the continuity and the speed of flow of red cells in the microcirculation. Despite the use of 
dexmedetomidine or fentanyl in septic patients, our results are in accordance with those presented by Silverstein (11), who analyzed the microcirculation in the oral mucosa of anesthetized dogs undergoing elective surgery. In the present study, mean values of TVD slightly fluctuated around 21.8 in all three evaluation time points under the CRI, while MFI mean values oscillated between 2.71 and 3.06.

Microvascular alterations are common in patients with sepsis, as several inflammatory mediators are involved, in addition to other coexisting physiological mechanisms that might impair microcirculation (9). Recent studies have shown that dexmedetomidine reduces the inflammatory response, decreases the interaction between leukocyte and endothelium and produces mild hypocoagulation, which contributes to microcirculation recruitment and, from a certain point of view, to minimizing the microvascular changes caused by sepsis $(12,13)$. These changes include endothelial cell dysfunction associated with molecular adhesion, increased leukocyte adhesion, glycocalyx degradation, vascular extravasation, microthrombi formation and local perfusion pressure alteration (2). The importance of the present study's findings is that the OPS imaging technique demonstrated that dexmedetomidine, in comparison with fentanyl, does not compromise microcirculation or tissue perfusion, which was also evidenced by serum lactate concentration and blood gas results.

In a similar research, sublingual microscopy was used in human patients randomly divided into two groups receiving either a propofol or dexmedetomidine CRI for postoperative sedation after cardiac surgery. The dexmedetomidine group showed higher values of DBS and vascular density, which demonstrated that dexmedetomidine, in comparison to propofol, possibly has a property of preserving the microcirculation in these patients (14).

As it is a potent selective alpha 2 agonist, dexmedetomidine has a dual alpha 2 adrenoceptor activation characteristic, since its effect in vascular smooth muscle cells results in vasoconstriction while the activation of receptors in endothelial cells and the inhibition of the sympathetic nervous system causes vasodilation $(3,13)$. The results presented here are consistent with the expected pharmacodynamics of dexmedetomidine, as a decrease in heart rate associated with an increase in blood pressure was observed, which was also shown in other experiments (15-17). This characteristic was also observed in critically ill dogs who received dexmedetomidine constant rate infusion in postoperative analgesia (18). Interestingly, in the present study mean heart rate values were higher than expected in the dexmedetomidine group: 87,74 and $71 \mathrm{bpm}$ in T0, T30 and T60, respectively. This finding is perhaps related to the fact that a dexmedetomidine loading dose was not used in this study. CRIs maintain lower plasma concentration levels than bolus injections and may therefore represent an option to avoid cardiovascular changes caused by the drugs (19). Dexmedetomidine's alpha 2 selective properties can be observed with slow intravenous administration of low and medium doses $(10-300 \mathrm{~g} / \mathrm{kg})$, whereas with higher doses (>1000 g/ $\mathrm{kg}$ ) or rapid intravenous infusion, both alpha 1 and alpha 2 activities can be observed in animals. Dexmedetomidine's pharmacokinetic properties might also explain why its CRI produces great results without a loading dose, since it has rapid distribution (a six-minute distribution half-life) (4). 
Dogs in DEX group showed an increase in MAP that was not observed in the fentanyl group. Indeed, before the beginning of the CRIs the dogs in DEX group showed lower MAP values compared with FENTA group; however, after the start of the CRIs, MAP mean values improved in DEX group and remained higher than FENTA group's values until the end of the infusion. Uilenreef (20) found that ASA I-II canine patients anesthetized with dexmedetomidine CRI (at $1-3 \mu \mathrm{g} / \mathrm{kg} / \mathrm{h}$ ) and isoflurane, following induction with propofol, showed stable blood pressure values, which were in fact considered to be relatively high for values usually observed with inhalation anesthesia protocols. Unlike humans, in dogs, alpha 2 agonists do not normally induce hypotension after an initial hypertension phase, probably on account of the fact that the vasoconstriction period is more sustained in this species, or because the loading doses intensify its effects $(16,21)$.

There were no significant differences in body temperature, $\mathrm{PaO} 2, \mathrm{SaO} 2, \mathrm{HCO} 3, \mathrm{AG}, \mathrm{Cl}, \mathrm{Na}, \mathrm{K}, \mathrm{BE}$ between groups. Pascoe et al. (22) found similar results when testing three different dexmedetomidine CRI doses $(0.1,0.5$ and $3 \mathrm{~g} / \mathrm{kg} / \mathrm{h})$ in healthy dogs to evaluate its impact on isoflurane MAC. A study that assessed dexmedetomidine's pharmacokinetics, cardiovascular and respiratory effects during a period of 24 hours of infusion concluded that although it caused hemodynamic changes, tissue oxygenation and acid-base balance parameters remained within acceptable limits (23), which corroborates with the blood gas results presented here. Despite the significant difference in $\mathrm{pH}$ between the groups, which suggested that the FENTA group (lower $\mathrm{pH}$ ) had a worse microcirculatory performance, this finding is probably associated with respiratory acidosis.

Mean values of serum lactate concentration remained below $2 \mathrm{mmol} / \mathrm{L}$ by the end of surgery (T60) in both groups without significant differences between them, indicating that effective fluid replacement and oxygenation were performed during the anesthetic procedure. Similar data were found by studies that evaluated the use of dexmedetomidine infusions in healthy patients, where no significant alterations of serum lactate concentration were observed (22). This marker is associated with better hospital outcome in humans when its levels are lower than $2 \mathrm{mmol} / \mathrm{L}$ (24), and a retrospective study by Houwink (25) reported that lactate was the most important mortality predictor in critically ill human patients. In the present study, lactate clearance was statistically significant in the DEX group, however it was not in the FENTA group, which reinforces the fact that dexmedetomidine CRI at this dose does not impair tissue perfusion.

In addition, delta temperature has been shown to be an important predictor of mortality in human ICU, and may be related to microcirculation (25). The present study found higher delta temperature values in the DEX group, however this information is not sufficient to conclude microcirculatory blood flow and oxygenation were inferior in dexmedetomidine group. More studies about delta temperature and the use of dexmedetomidine are needed.

Aiming to minimize potential adverse effects during the administration of dexmedetomidine boluses, such as hypertension followed by hypotension $(26,27)$, it was decided that the administration of a loading dose would not be performed, which however proved to be effective as evidenced by heart rate 
and blood pressure values, as well as microcirculatory parameters. The dexmedetomidine CRI dose was chosen based on studies that reported using doses between $1-5 \mathrm{~g} / \mathrm{kg} / \mathrm{h}$ in the anesthesia of healthy dogs $(20,22,28)$.

Low CRI doses result in greater plasma concentration constancy, better hemodynamic stability and faster biotransformation. Even though loading doses produce sedation more rapidly, they tend to cause greater hemodynamic instability in critically ill patients when administered as an intravenous bolus, as demonstrated by Pypendop (19), who compared CRI with intravenous bolus administration of alpha 2 agonists.

Furthermore, as dexmedetomidine has a short half-life, gradual discontinuation of the infusion leads to a faster return of the patient's level of consciousness $(29,30)$.

This study had a few limitations. The microcirculation monitoring technology is under constant improvement, therefore new equipment and software are always being introduced in the market. For this reason, the equipment used in this study could not be the most up-to-date that is currently available. However, the results obtained in this study were consistent with other studies', indicating that the technology used correlates well with more recent versions of the device. Furthermore, the surgical procedures were not performed by a single person, as there were two alternating surgeons that participated in the study.

\section{Conclusions}

Similar values of microcirculatory parameters and higher blood pressure demonstrated that dexmedetomidine does not compromise microcirculation compared to fentanyl, it improves macrohemodynamics instead.

\section{Abbreviations}

ACVIM: American college of veterinary internal medicine

CRI: constant rate infusion

DBS: De Backer Score

DEX: dexmedetomidine group

FENTA: fentanyl group

IM: intramuscular

IV: intravenous

MFI: microvascular flow index 
OHE: ovariohysterectomy

OPS: orthogonal polarization spectral

PPV: pulse pressure variation

SOFA: sequential organ failure assessment

TVD: total vessel density

\section{Declarations}

\section{Acknowledgements}

To CAPES (Coordination of Improvement of Higher Level Personnel)

\section{Availability of data and materials}

Data supporting our findings will be shared upon request

\section{Authors' contributions}

DTF and JKN designed the study, evaluated the data and revised the manuscript. JKN, LAG, MAAP conducted the experiments, collected and analysed all data, and helped to write the manuscript. AMA analysed the data and helped to write, edit and review the manuscript. MSFT and CMO performed the surgeries and review the manuscript. All authors read and approved the final manuscript.

\section{Competing interests}

The authors declare that they have no competing interests.

\section{Consent for publication}

Not applicable.

\section{Ethics approval and consent to participate}

The study was approved by the Ethical Committee of Animal Use at our university (protocol number 3578080716) and client-consent was obtained before entry of any dog into the study. 


\section{Funding}

CAPES (Coordination of Improvement of Higher Level Personnel) funding code 001.

\section{References}

1. Boller EM, Otto CM. Sepsis and septic shock. In: Silverstein DC, Hopper K, editors. Small Animal Critical Care Medicine. 2nd ed. St. Louis: Elsevier Saunders; 2015. p. 472-80.

2. Kara A, Akin S, Ince C. Monitoring microcirculation in critical illness. Curr Opin Crit Care [Internet]. 2016;22(5):444-52. Available from: http://content. wkhealth.com/linkback/openurl?sid = WKPTLP:landingpage\&an $=00075198-201610000-00007$

3. Liu X, Zhang K, Wang W, Xie G, Cheng B, Wang Y, et al. Dexmedetomidine Versus Propofol Sedation Improves Sublingual Microcirculation After Cardiac Surgery: A Randomized Controlled Trial. J Cardiothorac Vasc Anesth [Internet]. 2016;30(6):1509-15. Available from: http://dx.doi.org/10.1053/j.jvca.2016.05.038

4. Naaz S, Ozair E. Dexmedetomidine in current anaesthesia practice- a review. J Clin Diagnostic Res. 2014;8(10):GE01-GE04.

5. Penna GL, Salgado DR, Japiassú AM, Kalichsztein M, Nobre GF, Villela N, et al. Avaliação da microcirculação: uma nova arma no manejo da sepse? Rev Bras Ter Intensiva. 2011;23(21):352-7.

6. Singer M, Deutschman CS, Seymour CW, Shankar-Hari M, Annane D, Bauer M, et al. The Third International Consensus Definitions for Sepsis and Septic Shock (Sepsis-3). Jama [Internet]. 2016;315(8):801-10. Available from: http://jama.jamanetwork.com/article.aspx?doi = 10.1001/jama.2016.0287

7. De Backer D, Hollenberg S, Boerma C, Goedhart P, Büchele G, Ospina-Tascon G, et al. How to evaluate the microcirculation: report of a round table conference. Crit Care [Internet]. 2007;11(5):R101. Available from: http://ccforum.biomedcentral.com/articles/10.1186/cc6118

8. Groner W, Winkelman JW, Harris a G, Ince C, Bouma GJ, Messmer K, et al. Orthogonal polarization spectral imaging: a new method for study of the microcirculation. Nat Med. 1999;5(10):1209-12.

9. De Backer D, Creteur J, Preiser JC, Dubois MJ, Vincent JL. Microvascular blood flow is altered in patients with sepsis. Am J Respir Crit Care Med. 2002;166(1):98-104.

10. Trzeciak S, Cinel I, Dellinger RP, Shapiro NI, Arnold RC, Parrillo JE, et al. Resuscitating the microcirculation in sepsis: The central role of nitric oxide, emerging concepts for novel therapies, and challenges for clinical trials. Acad Emerg Med. 2008;15(5):399-413.

11. Silverstein DC, Pruett-Saratan A, Drobatz KJ. Measurements of microvascular perfusion in healthy anesthetized dogs using orthogonal polarization spectral imaging: Original study. J Vet Emerg Crit Care. 2009;19(6):579-87.

12. Ueki M, Kawasaki T, Habe K, Hamada K, Kawasaki C, Sata T. The effects of dexmedetomidine on inflammatory mediators after cardiopulmonary bypass. Anaesthesia. 2014;69(7):693-700. 
13. Miranda ML, Balarini MM, Bouskela E. Dexmedetomidine attenuates the microcirculatory derangements evoked by experimental sepsis. Anesthesiology [Internet]. 2015;122(3):619-30. Available from: http://search.ebscohost.com/login.aspx?direct = true\&AuthType = cookie,ip,shib\&db $=$ rzh\&AN $=107773015 \&$ site $=$ ehost-live

14. Liu X, Zhang K, Wang W, Xie G, Cheng B, Wang Y, et al. Dexmedetomidine Versus Propofol Sedation Improves Sublingual Microcirculation After Cardiac Surgery: A Randomized Controlled Trial. J Cardiothorac Vasc Anesth Doc MESA/microc dex Dexmedetomidine Versus Propofol Sedat Improv Sublingual Microcirc After Card Surg A Randomized Co [Internet]. 2017 [cited 2018 Feb 7];30:150915. Available from: https://ac.els-cdn.com/S1053077016301604/1-s2.0-S1053077016301604main.pdf?_tid $=35953 c 7 a-0 c 29-11$ e8-a0fc-00000aab0f6b\&acdnat $=$ 1518023357_f86cc64239f0e7195b42f19bac0c2427

15. Flacke WE, Flacke JW, Bloor BC, McIntee DF, Sagan M. Effects of dexmedetomidine on systemic and coronary hemodynamics in the anesthetized dog. J Cardiothorac Vasc Anesth [Internet]. 1993 Feb;7(1):41-9. Available from: http://www.ncbi.nlm.nih.gov/pubmed/8094301

16. Lawrence CJ, Prinzen FW, de Lange S. The effect of dexmedetomidine on the balance of myocardial energy requirement and oxygen supply and demand. Anesth Analg [Internet]. 1996 Mar;82(3):54450. Available from: http://www.ncbi.nlm.nih.gov/pubmed/8623959

17. Kuusela E, Raekallio M, Väisänen M, Mykkänen K, Ropponen H, Vainio O. Comparison of medetomidine and dexmedetomidine as premedicants in dogs undergoing propofol-isoflurane anesthesia. Am J Vet Res. 2001;62(7):1073-80.

18. Valtolina C, Robben JH, Uilenreef J, Murrell JC, Aspegren J, McKusick BC, et al. Clinical evaluation of the efficacy and safety of a constant rate infusion of dexmedetomidine for postoperative pain management in dogs. Vet Anaesth Analg. 2009 Jul;36(4):369-83.

19. Pypendop, Bruno H. Verstegen JP. Hemodynamic Effects of Medetomidine in the Dog: Vet Surg. 1998;27:612-22.

20. Uilenreef JJ, Murrell JC, McKusick BC, Hellebrekers LJ. Dexmedetomidine continuous rate infusion during isoflurane anaesthesia in canine surgical patients. Vet Anaesth Analg. 2008;35(1):1-12.

21. Vickery RG, Sheridan BC, Segal IS, Maze M. Anesthetic and hemodynamic effects of the stereoisomers of medetomidine, an alpha 2-adrenergic agonist, in halothane-anesthetized dogs. Anesth Analg [Internet]. $1988 \mathrm{Jul} ; 67(7): 611-5$. Available from:

https://www.ncbi.nlm.nih.gov/pubmed/2898219

22. Pascoe PJ, Raekallio M, Kuusela E, McKusick B, Granholm M. Changes in the minimum alveolar concentration of isoflurane and some cardiopulmonary measurements during three continuous infusion rates of dexmedetomidine in dogs. Vet Anaesth Analg. 2006;33(2):97-103.

23. Lin GY, Robben JH, Murrell JC, Aspegrén J, McKusick BC, Hellebrekers LJ. Dexmedetomidine constant rate infusion for 24 hours during and after propofol or isoflurane anaesthesia in dogs. Vet Anaesth Analg. 2008;35(2):141-53. 
24. Nguyen HB, Loomba M, Yang JJ, Jacobsen G, Shah K, Otero RM, et al. Early lactate clearance is associated with biomarkers of inflammation, coagulation, apoptosis, organ dysfunction and mortality in severe sepsis and septic shock. J Inflamm [Internet]. 2010;7:6. Available from: http://www.ncbi.nlm.nih.gov/pubmed/20181046

25. Houwink API, Rijkenberg S, Bosman RJ, van der Voort PHJ. The association between lactate, mean arterial pressure, central venous oxygen saturation and peripheral temperature and mortality in severe sepsis: a retrospective cohort analysis. Crit Care [Internet]. 2016;20(1):56. Available from: http://ccforum.com/content/20/1/56

26. Pandharipande PP, Pun BT, Herr DL, Maze M, Girard TD, Miller RR, et al. Effect of Sedation With Dexmedetomidine vs Lorazepam on Acute Brain Dysfunction in Mechanically Ventilated Patients. JAMA [Internet]. 2007 Dec 12;298(22):2644. Available from: http://jama.jamanetwork.com/article.aspx?doi = 10.1001/jama.298.22.2644

27. Constantin J-M, Momon A, Mantz J, Payen J-F, De Jonghe B, Perbet S, et al. Efficacy and safety of sedation with dexmedetomidine in critical care patients: A meta-analysis of randomized controlled trials. Anaesth Crit Care Pain Med [Internet]. 2016;35(1):7-15. Available from: http://linkinghub.elsevier.com/retrieve/pii/S2352556815001289

28. van Oostrom H, Doornenbal A, Schot A, Stienen PJ, Hellebrekers LJ. Neurophysiological assessment of the sedative and analgesic effects of a constant rate infusion of dexmedetomidine in the dog. Vet J. 2011;190(3):338-44.

29. Kuusela E, Vainio O, Kaistinen A, Kobylin S, Raekallio M. Sedative, analgesic, and cardiovascular effects of levomedetomidine alone and in combination with dexmedetomidine in dogs. Am J Vet Res. 2001;62(4):616-21.

30. Reade MC, O'Sullivan K, Bates S, Goldsmith D, Ainslie WRSTJ, Bellomo R. Dexmedetomidine vs. haloperidol in delirious, agitated, intubated patients: A randomised open-label trial. Crit Care. 2009;13(3):1-10.

\section{Tables}

Table 1. Laboratory tests data from all patients divided into the groups that received either fentanyl (FENTA) or dexmedetomidine (DEX) constant rate infusion (mean \pm standard deviation or median / interquatile range), with their respective comparision between groups $p$ values. 


\begin{tabular}{lcccc}
\hline Variable & All & FENTA & DEX & P value \\
& $(\mathbf{3 3})$ & $\mathbf{( 1 6 )}$ & $\mathbf{( 1 7 )}$ & \\
\hline Hematocrit & $35,4 \pm 6,3$ & $37 \pm 6,6$ & $34 \pm 0,139$ & 0,139 \\
\hline Hemoglobin & $12 \pm 2,5$ & $12,4 \pm 3$ & $11,6 \pm 1,9$ & 0,377 \\
\hline Leucocytes & $31.99 \pm 16,98$ & $26.528 \pm 12.225$ & $37.134 \pm 19.114$ & 0.068 \\
Protein & $7,5(7 / 8)$ & $7,5(7,1 / 8)$ & $7,5(7 / 7,8)$ & 0,748 \\
\hline Creatinine & $0.92(0.7 / 1.03)$ & $0.99(0.91 / 1.2)$ & $0.74(0.67 / 0.92)$ & 0.003 \\
\hline Urea & $30.80(20.9 / 46.7)$ & $30.1(21.8 / 51.6)$ & $35(18.4 / 40.9)$ & $<0.001$ \\
\hline ALT & $18.5(14.5 / 28.2)$ & $7.58(7.14 / 8)$ & $7.53(7 / 7.8)$ & 0.748 \\
\hline FA & $65.7(45.9 / 111.4)$ & $62.2(43 / 99)$ & $76.3(46.15 / 111.4)$ & 0.615 \\
\hline Platelet & $347.133 \pm 12.989$ & $309.133 \pm 120.946$ & $385.133 \pm 131.258$ & 0.110 \\
\hline
\end{tabular}

Hematocrit (\%); hemoglobin (g/dL); leukocytes (1000/mL); platelets (1000//mL); urea (mg/dL); creatinine (mg/dL); ALT: alanine transaminase (U/L); FA: alkaline phosphatase (U/L).

Table 2 Heart rate, blood pressure and delta temperature data from all patients divided into groups that received either fentanyl (FENTA) or dexmedetomidine (DEX) constant rate infusion (mean \pm standard deviation or median / interquatile range), with their respective comparision between groups $p$ values. 


\begin{tabular}{|c|c|c|c|c|}
\hline Parameter & $\begin{array}{l}\text { All } \\
(33) \\
\end{array}$ & $\begin{array}{c}\text { FENTA } \\
(16) \\
\end{array}$ & $\begin{array}{l}\text { DEX } \\
(17) \\
\end{array}$ & $P$ value \\
\hline HR BASAL & $122.6 \pm 22.3$ & $122 \pm 25$ & $122 \pm 20$ & 0.990 \\
\hline HR T0 & $102 \pm 25.5$ & $117 \pm 15.5$ & $87 \pm 25$ & $0.002 *$ \\
\hline HR T30 & $94.5 \pm 27.4$ & $116 \pm 22$ & $74 \pm 13$ & $<0.0001^{*}$ \\
\hline HR T60 & $92 \pm 27.2$ & $114 \pm 21$ & $71.3 \pm 10.8$ & $<0.0001^{*}$ \\
\hline HR FINAL & $100(91 / 120)$ & $120(100 / 127)$ & $88(72 / 100)$ & $0.005^{*}$ \\
\hline SAP BASAL & $160 \pm 25.5$ & $167 \pm 30$ & $152 \pm 18.7$ & 0.117 \\
\hline SAP T0 & 106.6 V 28.6 & $96.4 \pm 16$ & $116 \pm 34$ & $0.044^{*}$ \\
\hline SAP T30 & $115.7 \pm 27.1$ & $102.6 \pm 19.3$ & $128 \pm 28$ & $0.005^{*}$ \\
\hline SAP T60 & $114 \pm 29.6$ & $108.2 \pm 24.3$ & $119.5 \pm 33.6$ & 0.283 \\
\hline SAP FINAL & $171.3 \pm 30.6$ & $185 \pm 28.8$ & 157.326 .3 & $0.009 *$ \\
\hline MAP BASAL & $115 \pm 21.8$ & $126.3 \pm 23.8$ & $103.7 \pm 12$ & $0.002 *$ \\
\hline MAP T0 & $65.6 \pm 15.5$ & $59.7 \pm 11.1$ & $71.2 \pm 17.3$ & $0.031 *$ \\
\hline MAP T30 & $80.8 \pm 16.4$ & $72 \pm 13.3$ & $89 \pm 15$ & $0.001 *$ \\
\hline MAP T60 & $76.6 \pm 14.5$ & $73.2 \pm 11.4$ & $79.8 \pm 16.7$ & 0.199 \\
\hline MAP FINAL & $125.3 \pm 24.5$ & $132.7 \pm 27.7$ & $118 \pm 19.2$ & 0.103 \\
\hline DAP BASAL & $94.6 \pm 24.5$ & $108 \pm 23.8$ & $81.3 \pm 17.2$ & $0.001 *$ \\
\hline DAP T0 & $54(38 / 60)$ & $46(37 / 52.2)$ & $59(43 / 67)$ & 0.121 \\
\hline DAP T30 & $66.2 \pm 16$ & $57 \pm 11.3$ & $74.8 \pm 14.9$ & $<0.001^{*}$ \\
\hline DAP T60 & $61.6 \pm 13.1$ & $58 \pm 8$ & $65 \pm 16.1$ & 0.125 \\
\hline DAP FINAL & $100(95 / 113)$ & $110(95 / 120)$ & $95(87.5 / 107.5)$ & 0.250 \\
\hline$\triangle \mathrm{T}$ BASAL & $2.8(2.15 / 3.5)$ & $2.3(1.65 / 3.05)$ & $3.1(2.3 / 4)$ & 0.063 \\
\hline$\Delta \mathrm{T} \mathrm{T0}$ & $2.76 \pm 1.1$ & $1.9 \pm 1.17$ & $3.5 \pm 2.68$ & $0.031^{*}$ \\
\hline$\Delta \mathrm{T} \mathrm{T} 30$ & $2 \pm 1.4$ & $1.4 \pm 1.1$ & $2.6 \pm 1.5$ & $0.009 *$ \\
\hline$\Delta \mathrm{T} \mathrm{T} 60$ & $1.13 \pm 1.25$ & $1.13 \pm 1.2$ & $3.18 \pm 1.7$ & $<0.001^{*}$ \\
\hline$\Delta \mathrm{T}$ FINAL & $2.41 \pm 1.34$ & $2.14 \pm 1.35$ & $2.7 \pm 1.32$ & 0.285 \\
\hline
\end{tabular}

HR: heart rate (bpm); SBP: systolic blood pressure (mmHg); MAP: mean arterial pressure (mmHg); DBP: diastolic blood pressure $(\mathrm{mmHg}) ; \Delta \mathrm{T}$ : delta temperature; BASAL: baseline, 60 minutes before anesthetic 
induction; T0: before the beginning of the constant rate infusion; T30: 30 minutes after starting the constant rate infusion; T60: 60 minutes past the beginning of the constant rate infusion; FINAL: 60 minutes after extubation. * $p<0.05$ difference between FENTA and DEX groups.

Table 3 OPS index data from all patients divided into groups that received either fentanyl (FENTA) or dexmedetomidine (DEX) constant rate infusion (mean \pm standard deviation or median / interquatile range), with their respective comparision between groups $p$ values.

\begin{tabular}{lcccc}
\hline OPS index & All & FENTA & DEX & P value \\
& $(\mathbf{3 3})$ & $(\mathbf{1 6})$ & $(\mathbf{1 7 )}$ & \\
\hline TVD T0 & $21.8 \pm 1.47$ & $21.6 \pm 1.6$ & $22.1 \pm 1.3$ & 0.403 \\
TVD T30 & $21.8(20.5 / 22.7)$ & $21(20.16 / 22.3)$ & $22.6(20.56 / 22.8)$ & 0.093 \\
\hline TVD T60 & $21.8(20.7 / 22.2)$ & $21.6(20.7 / 22.16)$ & $21.8(21.5 / 22.3)$ & 0.505 \\
\hline & & & & \\
MFI T0 & $3.03 \pm 0.51$ & $3.13 \pm 0.48$ & $2.9 \pm 0.53$ & 0.267 \\
\hline MFI T30 & $2.71 \pm 0.56$ & $2.9 \pm 0.51$ & $2.52 \pm 0.54$ & $0.041 *$ \\
\hline MFI T60 & $3.06 \pm 0.46$ & $3.1 \pm 0.37$ & $2.95 \pm 0.52$ & 0.162 \\
\hline & & & & \\
\hline DBS T0 & $16.2 \pm 1.6$ & $16.3(15 / 17.6)$ & $16.2(15.4 / 17.1)$ & 0.909 \\
\hline DBS T30 & $16.5 \pm 1.9$ & $16.7(15.7 / 17.1)$ & $16.1(15.6 / 17)$ & 0.505 \\
\hline DBS T60 & $16 \pm 1.6$ & $16.4(15.15 / 17.07)$ & $16.2(14.8 / 16.8)$ & 0.732 \\
\hline
\end{tabular}

TVD: total vessel density $\left(\mathrm{mm} / \mathrm{mm}^{2}\right)$; MFI: vascular flow index; DBS: Backer score $\left(\mathrm{mm} / \mathrm{mm}^{2}\right)$; T0: before the beginning of the constant rate infusion; T30: 30 minutes after starting the constant rate infusion; T60: 60 minutes past the beginning of the constant rate infusion. ${ }^{*} p<0.05$ difference between FENTA and DEX groups.

Table 4 Blood gases, electrolytes concentrations, end-tidal carbon dioxide and isoflurane concentrations from all patients divided into groups that received either fentanyl (FENTA) or dexmedetomidine (DEX) constant rate infusion (mean \pm standard deviation or median / interquatile range), with their respective comparision between groups $p$ values. 


\begin{tabular}{|c|c|c|c|c|}
\hline Parameter & $\begin{array}{l}\text { All } \\
(33) \\
\end{array}$ & $\begin{array}{c}\text { FENTA } \\
(16) \\
\end{array}$ & $\begin{array}{l}\text { DEX } \\
(17) \\
\end{array}$ & $P$ value \\
\hline pH T0 & $7.32 \pm 0.06$ & $7.31 \pm 0.06$ & $7.32 \pm 0.07$ & 0.691 \\
\hline pH T60 & $7.31 \pm 0.07$ & $7.28 \pm 0.07$ & $7.34 \pm 0.06$ & $0.017 *$ \\
\hline $\mathrm{PaO}^{2} \mathrm{T0}$ & $254 \pm 78.4$ & $260 \pm 81.2$ & $248.5 \pm 77.8$ & 0.675 \\
\hline $\mathrm{PaO}^{2} \mathrm{~T} 60$ & $253.7 \pm 95.8$ & $270 \pm 88.6$ & $238.5 \pm 102.4$ & 0.356 \\
\hline $\mathrm{PaCO}^{2} \mathrm{T0}$ & $43 \pm 7.4$ & $44 \pm 7.5$ & $42 \pm 7.3$ & 0.448 \\
\hline $\mathrm{PaCO}^{2} \mathrm{~T} 60$ & $44 \pm 9.3$ & $48.2 \pm 8.8$ & $40.2 \pm 8.2$ & $0.011 *$ \\
\hline $\mathrm{SaO}^{2} \mathrm{TO}$ & $99.6(99.2 / 99.5)$ & $99.4(99.2 / 99.9)$ & $99.6(98.8 / 99.8)$ & 0.689 \\
\hline $\mathrm{SaO}^{2} \mathrm{~T} 60$ & $99.5(98.9 / 9.8)$ & $99.5(98.5 / 99.8)$ & $99.5(99.3 / 99.8)$ & 0.660 \\
\hline $\mathrm{HCO}_{3}^{-} \mathrm{TO}$ & $21.4 \pm 2.5$ & $21.7 \pm 2.8$ & $21.7 \pm 2.2$ & 0.502 \\
\hline $\mathrm{HCO}_{3}^{-} \mathrm{T} 60$ & $21.5 \pm 2.5$ & $21.8(20.8 / 22.85)$ & $20.8(19.4 / 21.8)$ & 0.077 \\
\hline AG T0 & $14.1 \pm 3.69$ & $14.4 \pm 3.7$ & $13.9 \pm 3.7$ & 0.691 \\
\hline AG T60 & $14.8 \pm 4$ & $14.9 \pm 4.1$ & $14.6 \pm 4$ & 0.835 \\
\hline $\mathrm{Cl}^{-} \mathrm{TO}$ & $113.5 \pm 5.6$ & $112 \pm 6.9$ & $114.8 \pm 3.8$ & 0.190 \\
\hline $\mathrm{Cl}^{-} \mathrm{T} 60$ & $112.3 \pm 5.1$ & $111 \pm 6.3$ & $113 \pm 3.8$ & 0.451 \\
\hline $\mathrm{Na}^{+} \mathrm{T0}$ & $145.7(143 / 150)$ & $146(141 / 150)$ & $145(144 / 149)$ & 0.871 \\
\hline $\mathrm{Na}^{+} \mathrm{T} 60$ & $145.2(142 / 148)$ & $146.7(142.8 / 149.5)$ & $144.4(142.3 / 146)$ & 0.348 \\
\hline $\mathrm{K}^{+} \mathrm{T} 0$ & $3.87(3.6 / 4.28)$ & $3.95(3.66 / 4.16)$ & $3.84(3.59 / 4.4)$ & 0.885 \\
\hline $\mathrm{K}^{+} \mathrm{T} 60$ & $3.87(3.59 / 4.28)$ & $3.87(3.47 / 4.23)$ & $4.33(4.08 / 4.6)$ & 0.009 \\
\hline
\end{tabular}




\begin{tabular}{lcccc} 
BE T0 & $-4,8 \pm 1,8$ & $-4.78 \pm 1.44$ & $-4.9 \pm 1.85$ & 0.811 \\
\hline BE T60 & $-4,6 \pm 1,6$ & $-4.9 \pm 1.9$ & $-4.76 \pm 1.93$ & 0.829 \\
\hline ETCO $^{2}$ T0 & $44.2 \pm 5.9$ & $44.5 \pm 5.2$ & $43.8 \pm 6.6$ & 0.747 \\
\hline ETCO $^{2}$ T30 & $42.3 \pm 7.9$ & $44.8 \pm 8.5$ & $39.8 \pm 6.6$ & 0.070 \\
\hline ETCO $^{2}$ T60 & $40.4 \pm 7.1$ & $44.1 \pm 8.1$ & $36.8 \pm 3.7$ & $0.003 *$ \\
\hline ISO T0 & $1.3(1.1 / 1.4)$ & $1.3(1.07 / 1.32)$ & $1.3(1.2 / 1.4)$ & 0.496 \\
\hline ISO T30 & $1.23 \pm 0.2$ & $1.3 \pm 0.17$ & $1.24 \pm 0.24$ & 0.473 \\
\hline ISO T60 & $1.2 \pm 0.24$ & $1.23 \pm 0.20$ & $1.14 \pm 0.27$ & 0.292 \\
\hline
\end{tabular}

PaO2: arterial oxygen partial pressure; PaCO2: arterial carbon dioxide partial pressure; SaO2: arterial oxygen saturation; HCO 3 - bicarbonate; AG: anion gap; Cl-: chloride; Na +: sodium; K +: potassium; BE: base excess; ETCO2: end-tidal carbon dioxide concentration; ISO: offend-tidal isoflurane concentration; T0: before the beginning of the constant rate infusion; T30: 30 minutes after starting the constant rate infusion; T60: 60 minutes past the beginning of the constant rate infusion. ${ }^{*} p<0.05$ difference between the FENTA and DEX groups.

\section{Figures}


SURGERY

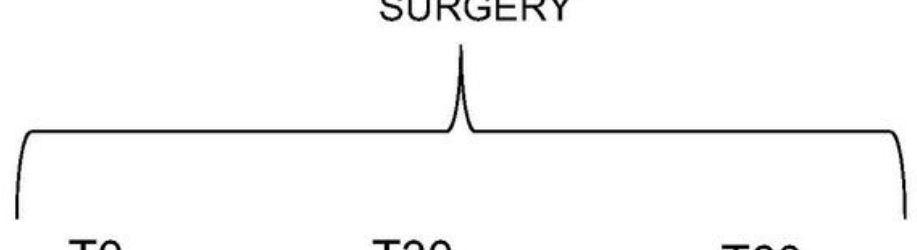

BASAL

T0

T30

T60

FINAL

\begin{tabular}{|l|}
\hline \multicolumn{1}{c}{$\boldsymbol{\Delta}$} \\
\hline HR; \\
SAP/MAP/DAP; \\
TOC \\
\hline
\end{tabular}

\begin{tabular}{|l|}
\multicolumn{1}{c|}{$\boldsymbol{\Delta}$} \\
\hline HR; \\
SAP/MAP/DAP; \\
TOC; \\
ETCO $;$ \\
OPS $^{\text {OPS }}$ iso \\
Lactate; \\
Glycemia; \\
Blood gas
\end{tabular}

\begin{tabular}{|l|}
\multicolumn{1}{c|}{$\boldsymbol{\Delta}$} \\
\hline $\mathrm{HR} ;$ \\
SAP/MAP/DAP; \\
TOC; \\
ETCO $;$ \\
OPS; $^{\text {ISO }}$ ex \\
\hline
\end{tabular}

HR:

SAP/MAP/DAP;

$\mathrm{T}^{\circ} \mathrm{C}$;

$\mathrm{ETCO}^{2}$;

OPS

$\mathrm{ISO}_{\mathrm{ex}}$;

Lactate;

Glycemia;

Blood gas

\section{Figure 1}

Parameters evaluated according to the evaluation times (BASAL; T0; T30; T60; FINAL). HR: heart rate; SAP: systolic arterial pressure; MAP: mean arterial pressure; DAP: diastolic arterial pressure; To C: temperature delta; ETCO2: expired carbon dioxide; OPS: spectral image by orthogonal polarization; ISOex: expired isoflurane concentration. 


\section{Lactato}

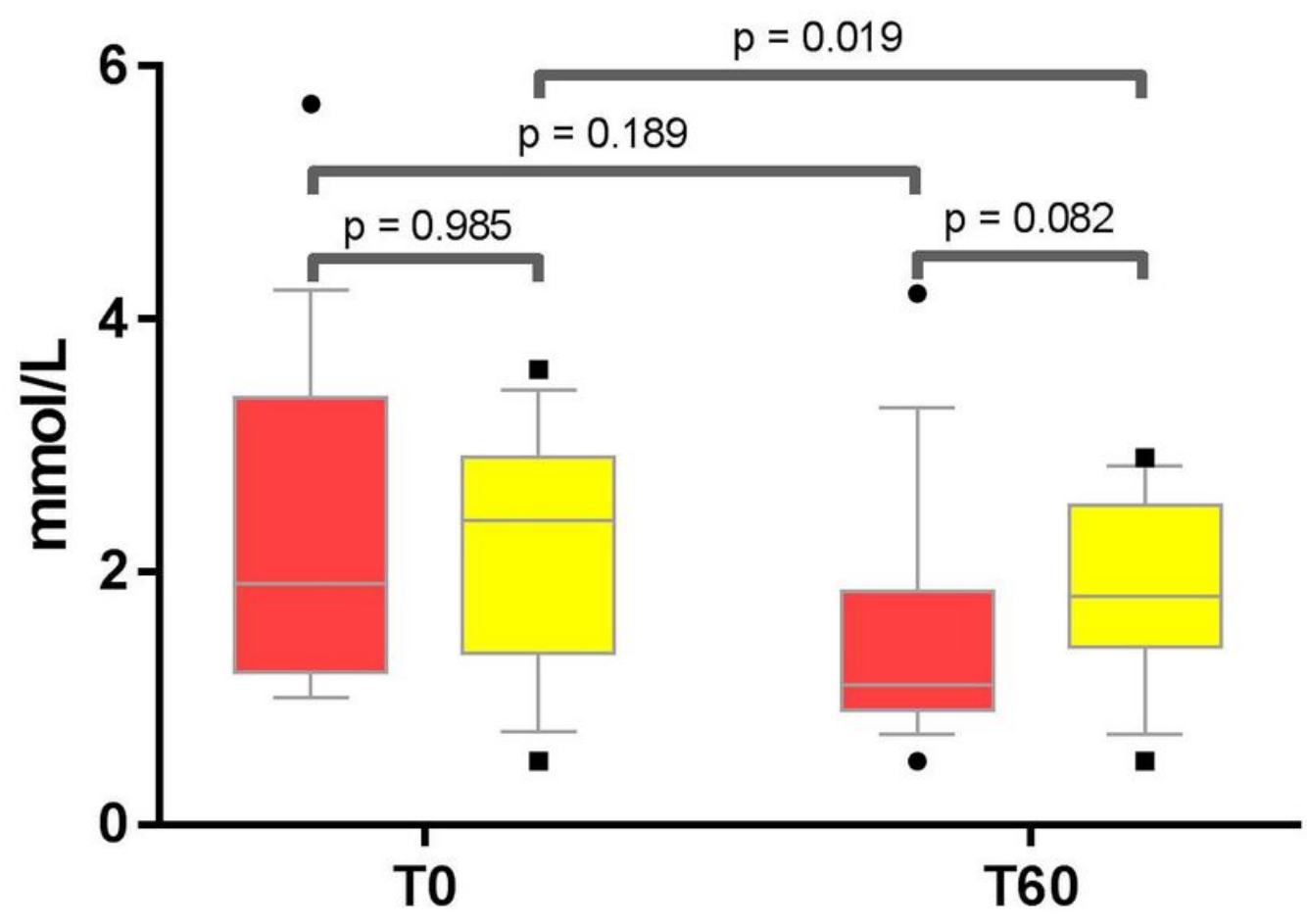

FENTA

$\square$ DEX

Figure 2

Serum lactate concentration boxplot sorted by groups that received either dexmedetomidine (DEX) or fentanyl (FENTA) constant rate infusion. T0: before the beginning of the constant rate infusion; T60: 60 minutes past the beginning of the constant rate infusion.

\section{Supplementary Files}

This is a list of supplementary files associated with this preprint. Click to download.

- NC3RsARRIVEGuidelinesChecklistfillable.pdf 